study (double blind, placebo controlled, crossover) comparing prehospital with in hospital thrombolytic treatment in 21 patients showed a mean global ejection fraction of $48 \%$ for those treated with tissue plasminogen activator outside the hospital and $44 \%$ for patients receiving tissue plasminogen activator on direct admission to the coronary care unit. Mean time to the start of active treatment in those receiving it outside hospital was 95 minutes, compared with 175 minutes for those receiving active treatment in the coronary care unit. No patient has suffered any serious side effects caused by the prehospital administration of tissue plasminogen activator.

Thus our results show that the administration of thrombolytic treatment by skilled mobile coronary care unit staff is feasible and safe. Prehospital adminis'ration of thrombolytic treatment can be started earlier than treatment in hospital even when patients are admitted directly to the coronary care unit without the added delay encountered in the casualty department. We believe that this early institution of treatment will result in significant improvement in myocardial function.

A J MCNEILL

Regional Medical Cardiology Centre,

A A J ADGEY

Royal Victoria Hospital,

Belfast BT12 6BA

1 GISSI Study Group. Effectiveness of intravenous thrombolytic treatment in acute myocardial infarction. Lancet 1986;i: 397-401.

2 Hugenholtz PG. Acute coronary obstruction in myocardial infarction: overview of thrombolytic therapy. Foumal of the American College of Cardiology 1987;9:1375-84.

SIR,-We were disappointed to read in Dr Tessa Richards's report on the meeting on thrombolytic therapy for acute myocardial infarction at the Royal Society of Medicine (18 July, p 198) that the time spent in the accident and emergency department is still regarded as potentially dangerous and wasteful.

Though the quoted median time of 89 minutes between arrival in the accident and emergency department and transfer to the coronary care unit for the named district general hospital is not optimal, the enlightened view should be that the accident and emergency department is the ideal environment for the organised reception, evaluation, and stabilisation of the patient with myocardial infarction. This includes initial treatment and therefore allows the prompt administration of thrombolytic drugs.

Departments in teaching hospitals and many district general hospitals are increasingly being staffed by career accident and emergency specialists. This renders obsolete the concept of the casualty department merely as a reception area for the patient to linger unsupervised, unmonitored, and untreated.

The tendency to rush the patient with acute myocardial infarction from home to ambulance into the accident and emergency department and to the coronary care unit as quickly as possible can only increase anxiety and the risk of precipitating ventricular fibrillation. Rather than being regarded as the epitome of efficiency, this should be discouraged.

The idea of bypassing accident and emergency departments altogether would offer no advantages to the patient with myocardial infarction. It would not allow those patients with non-cardiac problems to be diagnosed and redirected early for appropriate treatment, and the present $15 \%$ false positive rate of admissions to coronary care units might well increase with such a policy.

We agree that thrombolytic treatment is the most important advance in the early management of acute myocardial infarction since defibrillation. Constructive liaison between accident and emergency departments and coronary care units is essential to avoid delay and obtain maximum benefits.

\section{JOHN HEYWORTH} T F BEATTIE

Accident and Emergency Department,

Hope Hospital,

Salford M6 8HD

SIR, - We would like to comment on administering thrombolytic treatment to patients with acute coronary thrombosis, as discussed by Dr Tessa Richards (18 July, p 198).

It is important that this treatment is provided quickly, and to minimise delay it was suggested that "patients with chest pain could bypass the accident and emergency department altogether." Coronary care unit staff believe, however, that too many patients are admitted under their care without a diagnosis.

If this policy of bypassing the accident and emergency department were used we believe that coronary care units would be overwhelmed. In the two months from 1 August 1986 to 30 September 1986, 314 patients with chest pain were seen in one of our departments and $179(57 \%)$ were discharged. Of the 179 discharged, $136(76 \%)$ had referred themselves and only 43 , were referred by general practitioners. Of these 43 , only four were diagnosed as having ischaemic heart disease; the remainder had non-cardiac causes for chest pain. This tends to support the findings of Schor et al, who judged $28 \%$ of cases admitted after an initia diagnosis of myocardial infarction to be unneces sary admissions. ${ }^{2}$

Delay in admitting a patient to a coronary care unit does not necessarily mean delay in providing urgent treatment. It seems that the best policy would be for people with chest pain to be seen in well equipped accident and emergency departments and managed initially by accident and emergency staff with a protocol for case selection. In this way streptokinase (or an alternative) may be injected with the analgesic when the patient arrives in the resuscitation room.

Accident Unit,

Central Middlesex Hospital,

London NW10 7NS

S S TACHAKRA

Accident Unit,

King's College Hospital

London SE5 9RS

I Shosberg B, Fink N, Gibson G. Comparative analyses of emergency department treatment of chest pain. JACEP 1977;6:445-8

2 Schor S, Behar S, Modan B, et al. Disposition of presumed coronary patients from an emergency room. JAMA 1976; 236:941-3.

\section{The correlates of research success}

SIR,-Those who value medical research sufficiently highly, as young adults, to make considerable financial and other sacrifices to intercalate a BSc might reasonably be expected to value such research highly later.

The correlates of research success described by

Dr D C Evered and colleagues (25 July, p 241) may largely be related to the relative importance attached by different academics to research, teaching, administration, and clinical practice. Those achieving senior academic positions without the so called advantages of a BSc or an Oxbridge background may simply regard teaching as deserving more of their energies than publishing or being cited. If this is so then opting to intercalate a degree may be associated with subsequent "research success" simply through personal attitude. Allowing motivated and able students to choose to perform a research project may be beneficial, while requiring or even persuading them to do so may be counterproductive.

The fact that the BSc group published more and were cited more often than the Oxbridge group suggests that the active desire to undertake research may be the most important predictive factor of subsequent research success.

MRC Epidemiology Unit (South Wales),

JAMES GILBERT Cardiff CF2 3AS

SIR,-The paper by Dr D C Evered and colleagues on the correlates of research success (25 July, p 241) made interesting reading, particularly the fact that only $3.6 \%$ of senior academics are women. Even though there must have been unequal numbers of male and female graduates when the current group of professors and readers were starting their careers, it still seems that a disproportionately small number of women entered research. I find it hard to believe that this was because the women of 20 or 30 years ago were not up to scratch; I find it even harder to believe of today's graduates. Yet Dr Evered and coworkers say that there are no indications that the proportion of senior women academics is increasing.

Perhaps the tide is about to turn, but I suspect that research, like some of the hospital specialties, is still not seen as an attractive career choice, perhaps partly because of the perceived (and real) difficulties of combining career and family commitments (something, none the less, that most men have seemed and still seem to manage), but perhaps also because such a career choice is to some extent seen by both men and women as somehow unfeminine.

Whatever the case, the result is that around half of the potential research talent will continue to be squandered. This seems to be at best an inefficient use of resources and at worst a perpetuation of the unwitting discrimination entrenched in the medical system. Is it not time that greater efforts were made to encourage women to boldly go where few women have gone before?

Chase Farm Hospital

Abigail Seltzer Middlesex

\section{Lymphoedema of the arm}

SIR,-Professor N Browse (4 July, p 3) states that lymphoedema of the arm is rare. Primary lymphoedema may be rare, but secondary forms, usually associated with cancer or its treatment, constitute a considerable health service problem, particularly in specialist cancer centres. Unfortunately, there are no reliable epidemiological data on prevalence. The reported incidence after mastectomy varies from $7 \%$ to $63 \%$. $^{1}$ This variation relates to different operations, addition of radiotherapy, and length of follow up as well as criteria for diagnosis. The article by Kissin et al, to which Professor Browse refers, gives an incidence of lymphoedema after treatment for breast cancer ranging from $7 \%$ to $38 \%$ depending on treatment, radiotherapy being the most important risk factor. ${ }^{2}$ With more than 20000 new cases of breast cancer each year in England and Wales, an incidence of $10 \%$ would mean 2000 patients with lymphoedema a year, and for a condition that is incurable numbers are cumulative. Such figures take no account of arm lymphoedema arising from other causes-for example, after infection or treatment for other cancers. , 중 ) , 
We were pleased to see the recommendations for conservative measures but concerned by the impression given that for large, heavy limbs with reduced mobility surgery was the first option. Extensive experience reported by Foldi et al suggests that even severe and long term swelling may successfully be treated by a combination of massage, compression bandages or elastic hosiery, and exercise, ${ }^{3}$ surgery being required only to remove redundant skin. This has also been our experience. Effective treatment is, however, labour intensive. The best results are achieved at an early stage, when swelling is most reversible. Indeed, prophylatic treatment in high risk groups may be the way to limit the problem after treatment for cancer.

Raising the arm in a sling should be abandoned as it is uncomfortable and probably offers no greater benefit than positioning the arm at, or just above, heart level. Arm raising results in autoregulation with relative preservation of capillary pressure and flow. ${ }^{4}$ This reduction in precapillary vasoconstriction tends to buffer any benefit gained from lowering venous pressure. Limb raising in lymphoedema is thus pointless unless complemented by subsequent external support.

P S MORTIMER

Royal Marsden Hospital,

Surrey SM2 SPT

\section{F B REGNARD}

St Oswald's Hospice,

Newcastle upon Tyne NE3 1EE

1 Mortimer PS, Regnard CFB. Lymphostatic disorders. Br Med $\mathcal{J}$ 1986;293:347-8.

2 Kissin MW, Querci Della Rovere G, Easton D, Westbury G Risks of lymphoedema following treatment of breast disease. Brf Surg 1986;73:580-4.

3 Foldi E, Foldi $M$, Weifflader $H$. Conservative treatment of lymphoedema of the limbs. Angiology 1985;36:171-80.

4 Fagrell B, Svedman P, Osterfren J. The influence of hydrostatic pressure and contralateral cooling on capillary blood velocity and transculaneous oxygen fournal of Microcirculation and Clinical Experimentation 1982;1:163-71.

\section{Tenosynovitis in industry: menace or} misnomer?

SIR,-We are pleased that Mr Glyn Evans has considered the diagnosis of tenosynovitis (20 June, p 1569) and would agree that it has important implications regarding the choice of treatment. The term tenosynovitis, however, is commonly used to describe a collection of soft tissue injuries to the arm that would best be thought of under the heading of repetitive strain injuries.

In fact, the Department of Health and Social Security includes tenosynovitis in prescribed disease A8-traumatic inflammation of the tendons of the hand or forearm of the associated tendon sheaths-which also includes peritendonitis crepitans but is not intended to include conditions such as the carpal tunnel syndrome. Unfortunately, repetitive strain injuries are a group of conditions that we know too little about epidemiologically. They are undoubtedly associated with performing repetitive tasks on production line assembly work, but we do not know the likely incidence in a newly exposed workforce, the amount of spontaneous recovery that may occur as muscles develop, the incidence of recurrence, or whether long term problems ocur even after apparent recovery. Furthermore, we do not know how many of these injuries are caused by work or merely exacerbated by performing repetitive tasks. Perhaps not surprisingly, therefore, claims for disability under the heading tenosynovitis are considered even if tenosynovitis is not the true diagnosis.

Mr Evans also discussed methods of prevention and treatment. In our experience making the kinds of alteration to the workplace that industry will finance produces disappointing results, probably because there are numerous procedures that may cause these conditions. Repetitive strain injuries seem to be more related to high levels of production by fewer workers in "more efficient" workplaces. In addition, despite education, many workers do not report their injury until it has become chronic. Mr Evans correctly advocated rest as an important part of treatment, but it is increasingly difficult to persuade workers in whom the condition is of recent onset to take time off work. Hence we believe that in the current political and economic climate, where there is a demand for greater production from fewer workers, the problem is likely to grow.

Industry in its own way is attempting to address some of these problems. Some employers reject any applicants who have previously suffered any hand or arm discomfort at work. This seems a rather drastic measure, and we would encourage on site treatment of these problems and careful rehabilitation of workers so that they may return to their jobs.

Mr Evans's quoted statistics on the importance of tenosynovitis are now 10 years old. Its prevalence is likely to have increased since then, and within industry it is certainly perceived as a growing problem. We need more studies aimed at providing practical solutions, in which we would advocate a joint approach between occupational doctors and our orthopaedic colleagues. The Health and Safety Executive should consider funding such an approach.

B KING

J F WOLLASTON T G E GILLANDERS

\section{AMARC (Training Education and Safety) Limited}

Tyne and Wear NE31 1YN

\section{Type $A$ behaviour and ischaemic heart} disease

SIR,-Drs D W Johnston, D G Cook, and A G Shaper (11 July, p 86) are to be congratulated for documenting the association of high type A scores with a high prevalence of ischaemic heart disease in a British population, as many previously considered this to be a solely American phenomenon. It has always been attractive to suggest, as these authors have done, that the time pressured, activity prone type A behaviour exerts a sympathomimetic effect and exacerbates myocardial ischaemia. It is clear, however, from many studies that type A subjects report many more events in general, and somatic symptoms in particular, and hence it should come as no surprise to Dr Tom Sensky (11 July, p 69) that patients with chest pain but normal coronary arteries, or patients admitted to a coronary care unit with chest pain but without subsequent infarction, should have high type A scores. What is clear from this paper and that of the other British study is that type A behaviour is related to the reporting of chest pain in patients who also have coronary artery disease. ${ }^{1}$

The effect of the type A behaviour pattern on myocardial ischaemia documented during daily life has recently been studied by ambulatory ST Holter monitoring. ${ }^{2}$ Interestingly, type A subjects reported significantly more episodes of myocardial ischaemia as painful compared with type B subjects despite the fact that Holter monitoring showed no difference in the angiographic severity of their disease or the duration or severity of their ischaemia. The total duration of ischaemia and the total number of ischaemic events did not differ between the type A and type B patients, but type A patients reported one in two of the total number of ischaemic events as painful, whereas type B patients reported only one in four as painful. Furthermore, analysis of the heart rate in the minute before the onset of ST segment depression did not identify tachycardia as a more common precursor to ischaemia in patients with the type A behaviour pattern. ${ }^{3}$

Perception of ischaemic pain in angina pectoris is currently of great interest, and the personality of the patient seems to be increasingly pertinent. Possession of the type A behaviour pattern may therefore be advantageous in that it prompts likely patients with chest pain to see their doctors earlier than their type B peers. It may also, however, cause many others to undergo unwarranted coronary angiography, ${ }^{4}$ and this should be borne in mind when assessing the response to both medical and surgical treatment.

LEISA J FREEMAN

National Heart Hospital

London W1M 8BA

1 Gallacher JEJ, Yarnell JWG, Elwood PC, Phillips KM. Type A behaviour pattern and heart disease in men in the Caerphilly study. BrMed f 1984;289:732-3.

2 Freeman LJ, Nixon PGF. Type A behaviour and coronary artery disease. Br Heart f 1987;57:570.

3 Freeman LJ, Nixon PGF. The effect of type A behaviour pattern on myocardial ischaemia during daily life. Int 7 Cardiol (in press).

4 Bass C, Wade C. Type A behaviour: not specifically pathogenic? Lancet 1982;ii:1147-50.

SIR,-Dr D W Johnston and colleagues (11 July, p 86) present the first data on type $A$ behaviour and the incidence of ischaemic heart disease in British men. They conclude that a Bortner score suggesting type A behaviour has no predictive value for ischaemic heart disease. This conclusion may well be correct, but it cannot be justified from the analyses they present.

The original design of the regional heart study, of which this analysis is a part, was to investigate differences among areas in cardiovascular mortality, ${ }^{1}$ and Dr Johnston and coworkers point out that areas were chosen to represent the entire range of cardiovascular mortality. In their analysis, however, the sample is treated as a single homogeneous cohort and the possibility of an area effect on the prediction of ischaemic heart disease by type A behaviour is not considered. The uncertainty introduced by ignoring an effect of area means that differences between areas might obscure relations within areas. For example, poorer socioeconomic conditions, which are associated with greater cardiovascular mortality, ${ }^{2}$ of which the social class of the longest held occupation is not a comprehensive measure ${ }^{3}$ may also be associated with a lower distribution of type A scores. If so, the simple amalgamation of samples from "poor" and "rich" areas might result in an inverse association of type A behaviour with ischaemic heart disease, as the data of Dr Johnston and colleagues suggest.

As the regional heart study provides a unique opportunity to investigate differences among areas in type $A$ behaviour and the consistency of the association of ischaemic heart disease with type $A$ behaviour between areas there is a good case for an analysis in which the possible effects of area on the prediction of ischaemic heart disease by type $A$ behaviour are fully considered.

J E J GALLACHER

MRC Epidemiology Unit (South Wales) Cardiff CF2 3AS

1 Pocock SJ, Shaper AG, Cook DG, et al. British regional hear study: geographic variations in cardiovascular mortality, and study: geographic variations in cardiovascular mort

2 Marmot MG, Shipley MJ, Rose G. Inequalities in death-specific explanations of a general pattern? Lancet 1984; $;$ : 1003-6.

3 Cook DG, Cummins RO, Bartley MJ, Shaper AG. Health of unemployed middle-aged men in Great Britain. Lancet 1982;i:1290-4. 